\title{
Effect of electromagnetic radiation on the liver structure and ultrastructure of in utero irradiated rats
}

\author{
Katarína Holovská1, Viera Almášiová1, Sandra Andrašková1, Zuzana Demčišáková1, \\ Enikő Račeková2, Viera Cigánková ${ }^{1}$ \\ ${ }^{1}$ University of Veterinary Medicine and Pharmacy, Department of Anatomy, Histology and Physiology, \\ Košice, Slovak Republic \\ ${ }^{2}$ Slovak Academy of Sciences, Institute of Neurobiology of Biomedical Research Center, Košice, Slovak Republic
}

Received July 23, 2020

Accepted August 31, 2021

\begin{abstract}
The aim of this study was to observe the influence of electromagnetic radiation (EMR) on the structure and ultrastructure of the rat's liver. The pregnant rats used in the experiment were exposed to a pulsed microwave radiation (frequency of $2.45 \mathrm{GHz}$; mean power density of $2.8 \mathrm{~mW} / \mathrm{cm}^{2}$ ) daily for $2 \mathrm{~h}$, throughout their pregnancy. After delivery, the offspring was not exposed to EMR. Samples of the liver of 5-week-old offspring were subjected to histopathological evaluation. They were processed for light and transmission electron microscopy. Our results indicated that EMR did not cause pronounced changes in the structure of the liver of the investigated offspring. The size and shape of liver lobuli was preserved and the amount of connective tissue in the liver parenchyma did not increase. However, electron microscopy revealed changes in the shape and number of microvilli at the vascular pole of hepatocytes, and formation of vesicles of various shapes and sizes. The endothelial cells were swollen with larger fenestrations compared to the control group. The spaces of Disse were irregular and dilated. Even though these changes were only mild, further studies are needed to determine the effect of EMR and clarify its potential risk during pregnancy.
\end{abstract}

Microwave radiation, light microscopy, transmission electron microscopy, hepatocytes, microvilli

Microwaves ranging from $300 \mathrm{MHz}$ to $300 \mathrm{GHz}$ electromagnetic radiation (EMR) are widely used in various modern technologies, such as wireless networks, satellite and spacecraft communication, radar, medical devices, industrial heating, and many others. For example, Wi-Fi operates at frequency of $2.4 \mathrm{GHz}-5 \mathrm{GHz}$ (Zhang et al. 2015).

Results of the scientific studies conducted in this area are controversial and divide both the scientific community and the public into increasingly polarized groups (Haves 2017). Many scientific experiments which use animal models have demonstrated the adverse effect of EMR on various tissues and organs (Lee et al. 2006; Hanafy et al. 2010; El-Bediwi et a. 2011; Almášiová et al. 2017; Adebayo et al. 2019).

The effects of EMR can be thermal and non-thermal. The thermal effect is caused by absorption of waves resulting in the warming-up of tissues beyond physiological levels. Elevated temperatures can cause deactivation of enzymes, protein unfolding, or denaturation, and acceleration of cellular metabolism, for example when tissue is heated it can directly disrupt the hydrogen and disulphide bounds that maintain the tertial structure of proteins (Wilmink and Grundt 2012). The non-thermal effect involves mostly the direct interaction of EMR with various molecules in the tissues (Parasuraman et al. 2018). One of the most detectable non-thermal effects is the ion-flux (Yurish 2014). It has been noted that EMR affects the activity in cell membranes (sodium versus potassium ion conductivities) and non-selective channels, transmembrane potentials, and even the cell cycle (Romanenko et al. 2017). Despite extensive study, the mechanisms of interactions

Address for correspondence:

Doc. MVDr. Katarína Holovská, PhD.

Department of Anatomy, Histology and Physiology

University of Veterinary Medicine and Pharmacy

Phone: +421556429587

Komenského 73, 04181 Košice, Slovak Republic 
between live organisms and EMR have not yet been fully explained (K1vrak et al. 2017; Kocaman 2018; Galli et al. 2019). The cytoplasmic membrane and membranes of individual cellular organelles (mitochondria, endoplasmic reticulum) have been considered the primary sites of interaction. Some authors observed that EMR caused changes in the shape of cells and in the shape and arrangement of surface modifications (Chionna et al. 2003; Tenuzzo et al. 2006). The studies also provided evidence that EMR directly influences the structure of the cytoskeleton (Lange 2000; Gatrzke and Lange 2002; Chionna et al. 2003). In part, the cytoskeleton contains a network consisting of actin filaments, which helps to prevent deformation of cells and diffusive loss of organelles. Along with the transfer of pressure, strength of the cytoplasmic membrane and prevention of the lateral movement of membrane proteins, the cytoskeleton also forms the terminal web in the apical region of cells and reinforces surface modifications, such as microvilli (Dominguez and Holmes 2011).

A number of studies have investigated the influence of EMR on morphological changes in tissues and organs of adult animals, however, there is a lack of information on such changes in juvenile animals exposed to EMR in utero (Lee et al. 2006; Hanafy et al. 2010; El-Bediwi et a. 2011; Adebayo et al. 2019). The aim of our study was to observe the liver morphology of 5-week-old rats that had been exposed to pulsed EMR (frequency of $2.45 \mathrm{GHz}$, mean power density of $2.8 \mathrm{~mW} / \mathrm{cm}^{2}$ ) daily for $2 \mathrm{~h}$, throughout their intrauterine development.

\section{Materials and Methods}

\section{Experimental design}

The animals were bred at the animal facility of the Institute of Neurobiology, Biomedical Research Centre, Slovak Academy of Sciences. They were housed in conventional cages with ad libitum access to water and food. Before the onset of the experiment, females of the Wistar Albino rats $(n=6)$, approximately 3 months old, were mated with males $(n=1)$ of the same strain. The pregnant females were divided into control $(n=3)$ and irradiated $(n=3)$ groups. The experimental animals (pregnant females) were exposed to pulsed microwave radiation at the frequency of $2.45 \mathrm{GHz}$ and mean power density of $2.8 \mathrm{~mW} / \mathrm{cm}^{2}$, for $2 \mathrm{~h}$ per day throughout the pregnancy. The exposure chamber $(100 \times 80 \times 70 \mathrm{~cm})$ was purposely designed for the exposure of free-moving pregnant rats, and the uniformity of radiation was controlled with a spectrum analyzer (Šimaiová et al. 2019). The control mates were kept under standard conditions without exposure to EMR. Their offspring were no longer exposed to EMR. Five-week-old male offspring of both control $(n=5)$ and experimental $(n=5)$ animals was anaesthetized with chloral hydrate (Central Chem, Slovakia) and perfused transcardially with a solution of $4 \%$ paraformaldehyde in $0.1 \mathrm{M}$ phosphate buffer (MP Biomedicals, France). After that, liver samples were collected. All procedures were approved by the Ethics Committee of the Institute of Neurobiology, Biomedical Research Centre, Slovak Academy of Sciences, in accordance with the current Slovak Republic legislation.

\section{Histopathological analysis - light and transmission electron microscopy}

Samples for light microscopy were fixed in 4\% neutral formaldehyde (Mikrochem s.r.o., Pezinok, Slovakia), dehydrated through successive alcohol series and finally embedded in paraffin wax. Five to seven $\mu \mathrm{m}$ thick tissue sections were stained with haematoxylin and eosin (HE) for structure, and Picrosirius red $(0.1 \%$ Picrosirius red in saturated aqueous picric acid; Sigma-Aldrich, Saint Louis, USA) for collagen, then examined under a light microscope Olympus CX 43 (Olympus, Japan) and documented with a camera (Promicra, Prague, Czech Republic).

The tissue samples for transmission electron microscopy $\left(1 \mathrm{~mm}^{3}\right)$ were fixed in $3 \%$ glutaraldehyde (SigmaAldrich, Bratislava, Slovak Republic) and postfixed in 1\% osmium tetraoxide (both in $0.1 \mathrm{M}$ cacodylate buffer, $\mathrm{pH}$ 7.3, Fluka Chemie AG, Buchs, Switzerland). After dehydration in acetone, they were transferred to propylene oxide and embedded in Durcupan ${ }^{\mathrm{TM}}$ ACM (Sigma-Aldrich Chemie GmbH, Taufkirchen, Germany). The ultrathin sections (90-120 nm) were double contrasted with 1\% uranyl acetate (Sigma-Aldrich, Slovak Republic) and 0.3\% lead citrate (Merck, Bratislava, Slovak Republic) and examined under an electron microscope Tesla BS 500 (Tesla Brno, Czech Republic).

\section{Light microscopy}

\section{Results}

The liver in the control group had a standard morphological structure. Hepatocytes were polygonal in shape, with acidophilic cytoplasm and round euchromatic nuclei. The hepatocytes were arranged in anastomosing cords, separated by liver sinusoids. Sirius red 
staining revealed normal lobular architecture and normal distribution of collagen (Plate $\mathrm{V}$, Figs $1 \mathrm{~A}$ and 1B).

In the experimental group, we did not observe significant structural changes in the liver. The size and shape of liver lobules was preserved. No inflammatory changes were detected in the liver tissue and the amount of connective tissue in the portobiliary spaces was not increased. The hepatocytes retained their size and shape and the liver sinusoids showed no dilatation or hyperaemia (Plate V, Figs 1C and 1D).

\section{Transmission electron microscopy}

In the control group, the liver cells had a normal ultrastructure. The cytoplasm of hepatocytes contained well-formed mitochondria, rough endoplasmic reticulum, and sporadically placed lipid droplets. Intercellular junctions between adjacent cells were clearly visible. The cytoplasmic membrane of hepatocytes formed short microvilli that protruded into both spaces of Disse and the narrow bile canaliculi. The space of Disse was separated from the sinusoids by discontinuous endothelial cells. The cytoplasm of endothelial cells contained a compact oval nucleus, mitochondria and pinocytotic vesicles (Plate VI, Figs 2A and 2B).

In the experimental group, we observed ultrastructural changes of varying extent. In unchanged regions of the liver parenchyma, the ultrastructure of hepatocytes and their organelles such as mitochondria and rough endoplasmic reticulum were preserved. In some cells, lipid droplets were clearly visible.

In many hepatocytes, numerous vesicles of various shapes and sizes were observed. Some of them were homogenous, but the other ones contained small electron-dense granules. In these cells the mitochondria were moderately swollen, and in some regions of the parenchyma, the spaces of Disse were dilated and irregular. The endothelial cells were swollen with large fenestrations. In the same areas the cell membrane of hepatocytes (at the vascular pole) was almost smooth. Microvilli extended into the spaces of Disse were changed and their number was reduced.

In all hepatocytes, the bile canaliculi and the microvilli extending into their lumen displayed intact morphology (Plate VII, Figs 3A and 3B).

\section{Discussion}

EMR affects various processes that take place in the cells, such as synthesis of proteins and DNA transcription (Del Re et al. 2019), transfer of ions through the cytoplasmic membrane and their subsequent accumulation in the cells (Lange 2000; Sun et al. 2016), as well as changes in cytoskeleton organisation (Glade and Tabony 2005; Wu et al. 2018).

The present study showed that exposure to EMR of a frequency of $2.45 \mathrm{GHz}$ and mean power density of $2.8 \mathrm{~mW} / \mathrm{cm}^{2}$ caused no pronounced morphological changes in the liver structure of 5-week old rats irradiated in utero as examined under light microscopy. However, our previous experiments revealed moderate hyperaemia, dilatation of liver sinusoids, and small inflammatory foci in the centre of liver lobules of 3-week-old rats that had been exposed to EMR postpartum $(2.45 \mathrm{GHz}, 3 \mathrm{~h}$ daily for 3 weeks) (Holovská et al. 2015). Similar morphological changes induced by EMR in the liver of experimental animals were also observed by other authors. Al-Glaib et al. (2008) investigated the effect of EMR from mobile phones (850-1900 MHz, $1 \mathrm{~h}$ to $12 \mathrm{~h}$ daily for 10 days) on mice and observed inflammatory changes in portobiliary spaces and vacuolisation of hepatocytes. Marked dilatation of liver sinusoids and congestion of central veins as well as hyperchromatic nuclei in hepatocytes of rats (1800 MHz for 5 weeks) were observed by Adebayo et al. (2019). Hanafy et al. (2010) also observed congestion of the sinusoids and the central veins ( $900 \mathrm{MHz}, 1 \mathrm{~h}$ daily for 4 weeks). Only mild inflammation in portal 
spaces and increased occurrence of macrophages and lymphocytes in rats was detected by Mortazavi et al. (2016) (900-1800 MHz, 3 or $6 \mathrm{~h}$ for 7 days). However, investigations of the long-term effect of EMR (20 kHz, $8 \mathrm{~h}$ daily,12-18 months) on rats conducted by Lee et al. (2006) showed neither changes in biochemical parameters nor alternations in the structure of tissues and organs.

In utero exposure to EMR in our experiment induced no marked morphological changes in the structure of rat liver as examined under light microscopy. However, electron microscopy revealed changes in the ultrastructure of hepatocytes that involved the occurrence of vesicles of various shapes and size and moderately dilated mitochondria. Similar ultrastructural changes were observed in 3-week-old rats irradiated postpartum, but the ultrastructures of the spaces of Disse and endothelial cells were preserved (Holovská et al. 2015). In the liver of 5-week-old rats, alterations in the endothelial cells and spaces of Disse were detected along with a decrease in the number of microvilli at the vascular pole of hepatocytes. In hepatocytes, microvilli are situated at the biliary pole where secretion of bile into the biliary capillary takes place, as well as at the vascular pole where compounds are resorbed from the blood plasma (Gissen and Arias 2015). Each microvillus contains a core of actin filaments which maintains the shape of the microvilli (Ishiia et al. 1991). It has been observed that EMR may cause a reorganization or depolymerisation of actin filaments in the cells which subsequently leads to changes in the shape of cells as well as the shape of surface modifications (Gatrzke and Lange 2002; Chionna et al. 2003). In addition, some studies have reported that these changes are probably related to changes in the concentration of calcium ions $\left(\mathrm{Ca}^{2+}\right)$ (Chionna et al. 2003; Tenuzzo et al. 2006). Chionna et al. (2003) observed the effect of the static magnetic field on lymphocytes. They revealed rearrangement of F-actin filaments which induced modifications of the cell shape. The lymphocytes lost their round shape and become irregularly elongated with lamellar shaped microvilli. Similar changes were observed by Santoro et al. (1997) in lymphocytes that were exposed to the magnetic field $(50 \mathrm{~Hz})$ for $72 \mathrm{~h}$. The magnetic field caused changes in plasma membrane morphology which were manifested by the loss of microvilli. Our study also showed that EMR may cause marked changes in the shape and arrangement of microvilli of the hepatocytes. The changes observed in our experiment could be a consequence of a disturbance of the cytoskeleton, especially actin filaments or changes in the intracellular $\mathrm{Ca}^{2+}$ concentration (Wu et al. 2018).

The majority of scientific studies were focused on the effect of EMR on cell lines and adult experimental animals. There are no studies in the available literature dealing with the effect of EMR on the structure of liver in juvenile animals irradiated in utero. The results showed that the effect of microwave radiation at a frequency of $2.45 \mathrm{GHz}$ and mean power density of $2.8 \mathrm{~mW} / \mathrm{cm}^{2}$ had an adverse effect on the liver. The experimental animals (5-week-old rats) were irradiated only during their intrauterine development and were not exposed to EMR after birth. Light microscopy did not show any pronounced morphological changes in the liver, but electron microscopy revealed changes in the ultrastructure of the cells. Even though these changes were only mild, further studies are needed to determine the effect of EMR and clarify its potential risk during pregnancy.

\section{Acknowledgements}

The authors thank Paul McEvilly, DVM, for English correction of the manuscript. This study was supported by the VEGA project from the Slovak Ministry of Education No. 1/0060/18.

\section{References}

Adebayo EA, Adeeyo AO, Ogundiran MA, Olabisi O 2019: Bio-physical effects of radiofrequency electromagnetic radiation (RF-EMR) on blood parameters, spermatozoa, liver, kidney and heart of albino rats. J King Saud Univ-Sci 31: 813-821 
Al-Glaib B, Al-Dardfi M, Al-Tuhami A, Elgenaidi A, Dkhil M 2008: A technical report on the effect of electromagnetic radiation from a mobile phone on mice organs. Libyan J Med 3: 8-9

Almášiová V, Holovská K, Šimaiová V, Beňová K, Raček A, Račeková E, Martončíková M, Mihálik J, Horváthová F, Tarabová L, Slanina T, Cigánková V 2017: The thermal effect of $2.45 \mathrm{GHz}$ microwave radiation on rat testes. Acta Vet Brno 86: 413-419

Chionna A, Dwikat M, Panzarini E, Tenuzzo B, Carlà EC, Verri T, Pagliara P, Abbro L, Dini L 2003: Cell shape and plasma membrane alterations after static magnetic fields exposure. Eur J Histochem 47: 299-308

Del Re B, Bersani F, Giorgi G 2019: Effect of electromagnetic field exposure on the transcription of repetitive DNA elements in human cells. Electromagn Biol Med 38: 262-270

Dominguez R, Holmes KC 2011: Actin structure and function. Annu Rev Biophys 40: 169-186

El-Bediwi AB, El-kott AF, Saad M, Eid E 2011: Effects of electromagnetic radiation produced by mobile phone on some visceral organs of rat. J Med Sci 11: 256-260

Galli C, Pedrazzi G, Guizzardi S 2019: The cellular effects of pulsed electromagnetic fields on osteoblasts. Bioelectromagnetics 40: 211-233

Gatrzke J, Lange K 2002: Cellular target of weak magnetic fields: ionic conduction along actin filaments of microvilli. Am J Physiol Cell Physiol 283: 1333-1346

Gissen P, Arias IM 2015: Structural and functional hepatocyte polarity and liver disease. J Hepatol 63: 1023-1037

Glade N, Tabony J 2005: Brief exposure to high magnetic fields determines microtubule self-organisation by reaction-diffusion processes. Biophys Chem 115: 29-35

Hanafy LK, Sawsan H, Karam H, Saleh A 2010: The adverse effect of mobile phone radiation on some visceral organs. Res J Medicine \& Med Sci 5: 95-99

Haves M 2017: When theory and observation collide: Can non-ionizing radiation cause cancer? Environ Pollut 221: $501-505$

Holovská K, Almášiová V, Cigánková V, Beňová K, Račeková E, Martončíková M 2015: Structural and ultrastructural study of rat liver influenced by electromagnetic radiation. J Toxicol Environ Health Part A 78: 353-356

Ishiia M, Washioka H, Tonosaki A, Toyota T 1991: Regional orientation of actin filaments in the pericanalicular cytoplasm of rat hepatocytes. Gastroenterology 101: 1663-1672

Kivrak EG, Yurt KK, Kaplan AA, Alkan I, Altun G 2017: Effects of electromagnetic fields exposure on the antioxidant defense system. J Microsc Ultrastruct 5: 167-176

Kocaman A, Altun G, Kaplan AA, Deniz ÖG, Yurt KK, Kaplan S 2018: Genotoxic and carcinogenic effects of non-ionizing electromagnetic fields. Environmental Research 163: 71-79

Lange K 2000: Microvillar ion channels. Cytoskeletal modulation of ion fluxes. J Theor Biol 206: 561-584

Lee HJ, Kim SH, Choi SY, Gimm YM, Pack JK, Choi HD, Lee YS 2006: Long-term exposure of Sprague Dawley rats to $20 \mathrm{kHz}$ triangular magnetic fields. Int J Radiat Biol 82: 285-291

Mortazavi SMJ, Owji SM, Shojaei-fard MB, Ghader-Panah M, SMortazavi AR, Tavakoli-Golpayegani A, Haghani M, Taeb S, Shokrpour N, Koohi O 2016: GSM 900 MHz microwave radiation-induced alterations of insulin level and histopathological changes of liver and pancreas in rat. J Biomed Phys Eng 6: 235-242

Parasuraman S, Xin EY, Zou LN 2018: Health hazards with electromagnetic radiation. Int J Pharma Investig 8:157-163

Romanenko S, Begley R, Harvey AR, Hool L, Wallace VP 2017: The interaction between electromagnetic fields at megahertz, gigahertz and terahertz frequencies with cells, tissues and organisms: risks and potential. J R Soc Interface 14: 1-22

Santoro N, Lisi A, Pozzi D, Pasquali E, Serafino A, Grimaldi S 1997: Effect of extremely low frequency (ELF) magnetic field exposure on morphological and biophysical properties of human lymphoid cell line (Raji). Biochim Biophys Acta 1357: 281-290

Šimaiová V, Almášiová V, Holovská K, Kisková T, Horváthová F, Ševčíková Z, Tóth Š, Raček A, Račeková E, Beňová K, Dvořák P, Cigánková V 2019: The effect of $2.45 \mathrm{GHz}$ non-ionizing radiation on the structure and ultrastructure of the testis in juvenile rats. Histol Histopathol 34: 391-403

Sun ZC, Ge JL, Guo B, Guo J, Hao M, Wu YC, Yi-an Li, Ting L, Pan-tong Y, Yan-ai M, Yi F, Lei X 2016: Extremely low frequency electromagnetic fields facilitate vesicle endocytosis by increasing presynaptic calcium channel expression at a central synapse. Sci Rep 18: 1-11

Tenuzzo B, Chionna A, Panzarini E, Lanubile R, Tarantino P, Di Jeso B, Dwikat M, Dini L 2006: Biological effects of $6 \mathrm{mT}$ static magnetic fields: a comparative study in different cell types. Bioelectromagnetics 27 : 560-577

Wilmink GJ, Grundt JE 2012: Terahertz Radiation: Sources, Applications, and Biological Effects. In: Lin JC (Ed.): Electromagnetic Fields in Biological Systems. CRC Press, Boca Raton, FL, USA. 430 p.

Wu X, Du J, Song W, Cao M, Chen S, Xia R 2018: Weak power frequency magnetic fields induce microtubule cytoskeleton reorganization depending on the epidermal growth factor receptor and the calcium related signaling. PLoS One 13: 1-27

Yurish S 2014: Sensors and Biosensors, MEMS Technologies and its Applications. Ifsa Publishing, pp. 307-308

Zhang Y, Li Z, Gao, Y, Zhang C 2015: Effects of fetal microwave radiation exposure on offspring behavior in mice. J Radiat Res 56: 261-268 
Plate V

Holovská K. et al.: Effect ... pp. 315-319
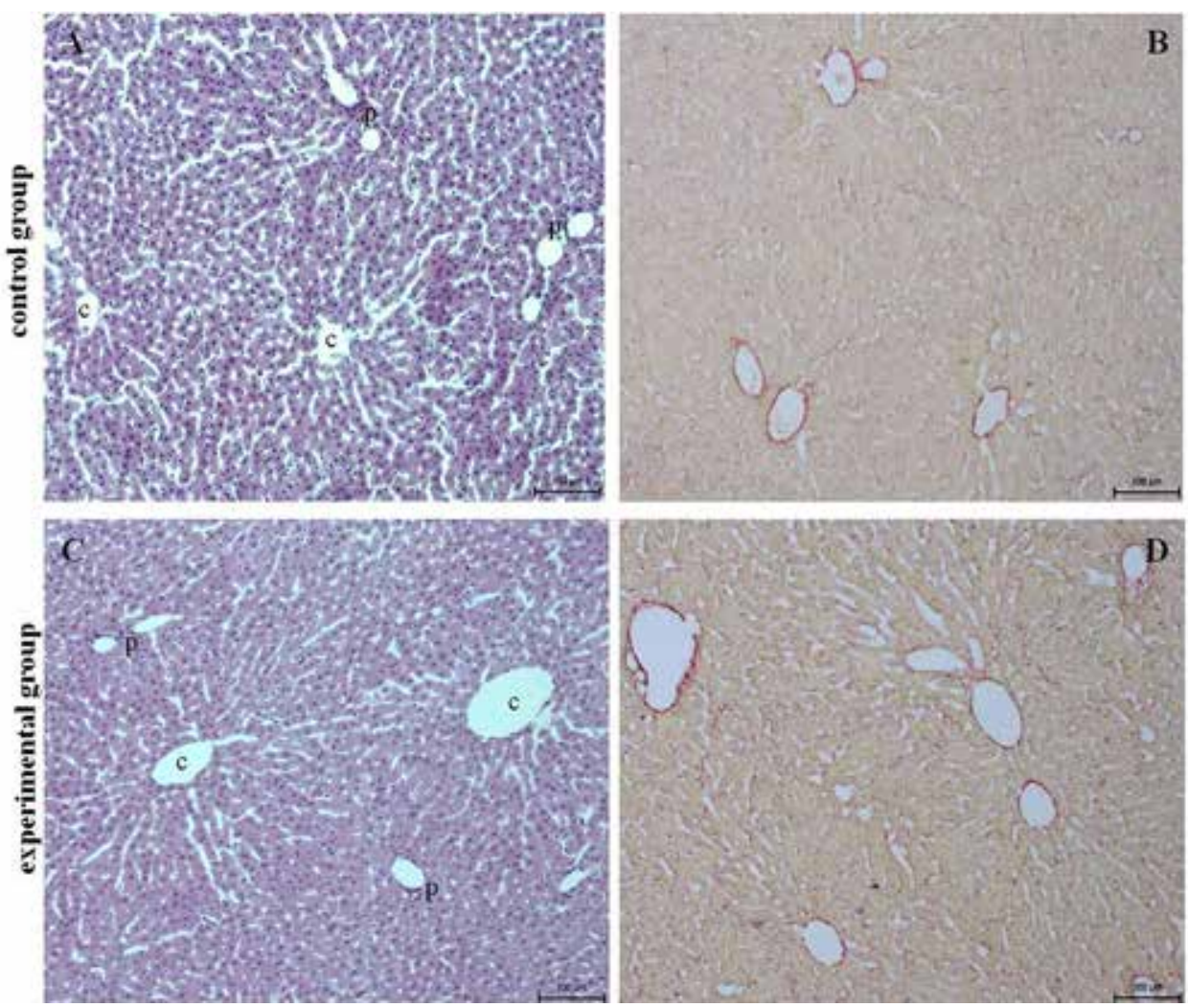

Fig. 1. Microphotograph of the liver in the control group (A, B), and in the experimental group (C, D), $\mathrm{c}-\mathrm{v}$. centralis, $\mathrm{p}$ - portobiliar space. Sections are stained with HE (A, C), and Picrosirius red (B, D). Scale bar $100 \mu \mathrm{m}$. 


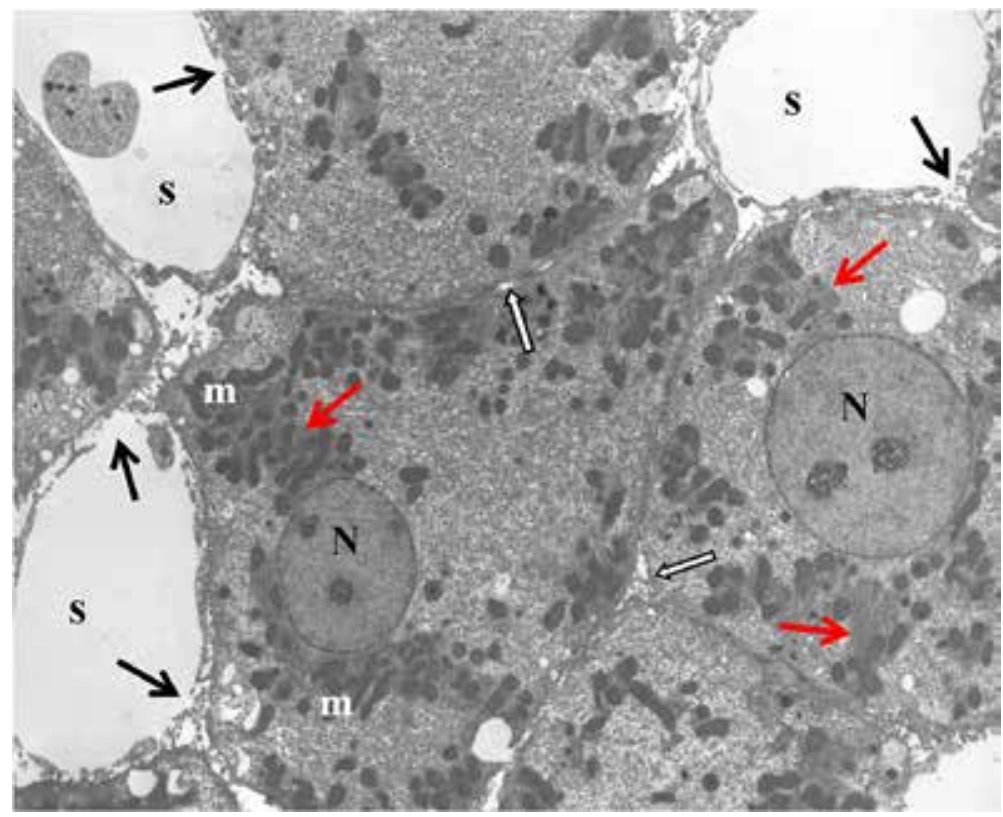

Fig. 2A. Electron micrograph of the liver in the control group, $\mathrm{N}$ - nucleus, red arrows - rough endoplasmic reticulum, $\mathrm{m}$ - mitochondria, s - liver sinusoids, black arrows - fenestrations in endothelial cells, white arrows - bile canaliculus, magnification $\times 4000$.

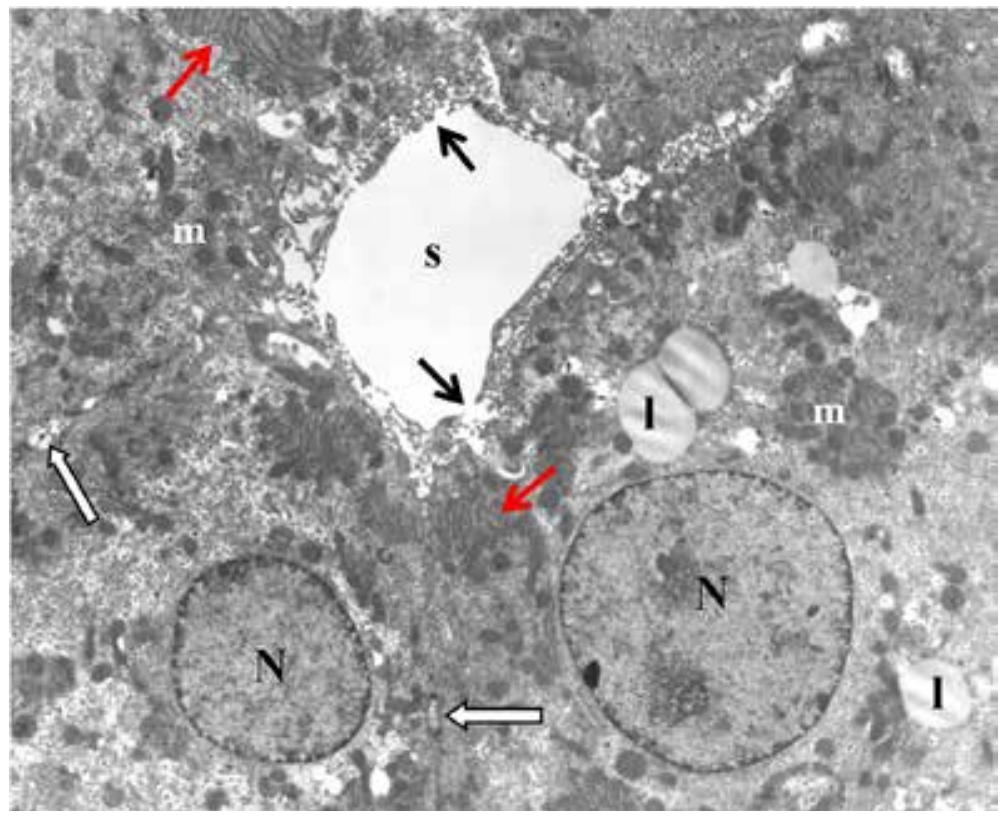

Fig. 2B. Electron micrograph of liver in the control group, $\mathrm{N}$ - nucleus, red arrows - rough endoplasmic reticulum, $\mathrm{m}$ - mitochondria, $\mathrm{s}$ - liver sinusoid, black arrows - fenestrations in endothelial cells, 1 - lipid droplet, white arrows - bile canaliculus, magnification $\times 5300$. 


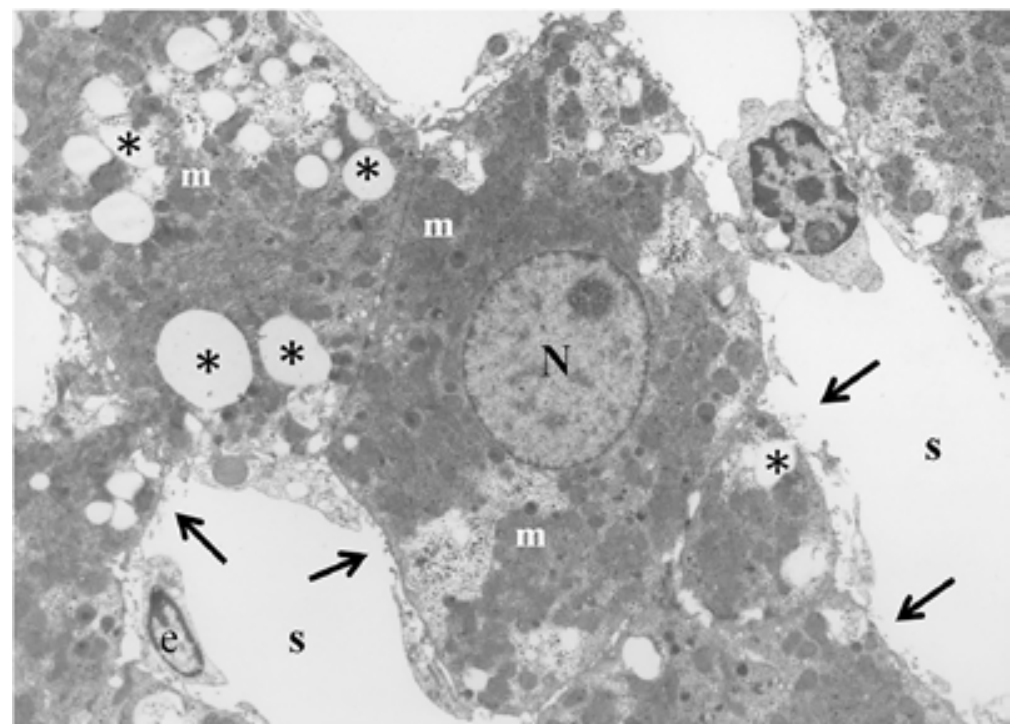

Fig. 3A. Electron micrograph of the liver in the experimental group, $\mathrm{N}$ - nucleus, $\mathrm{m}$ - mitochondria, $\mathrm{s}$ - liver sinusoid, e - endothelial cell, black arrows - fenestrations in endothelial cells, asterisks - vesicle, magnification $\times 4500$.

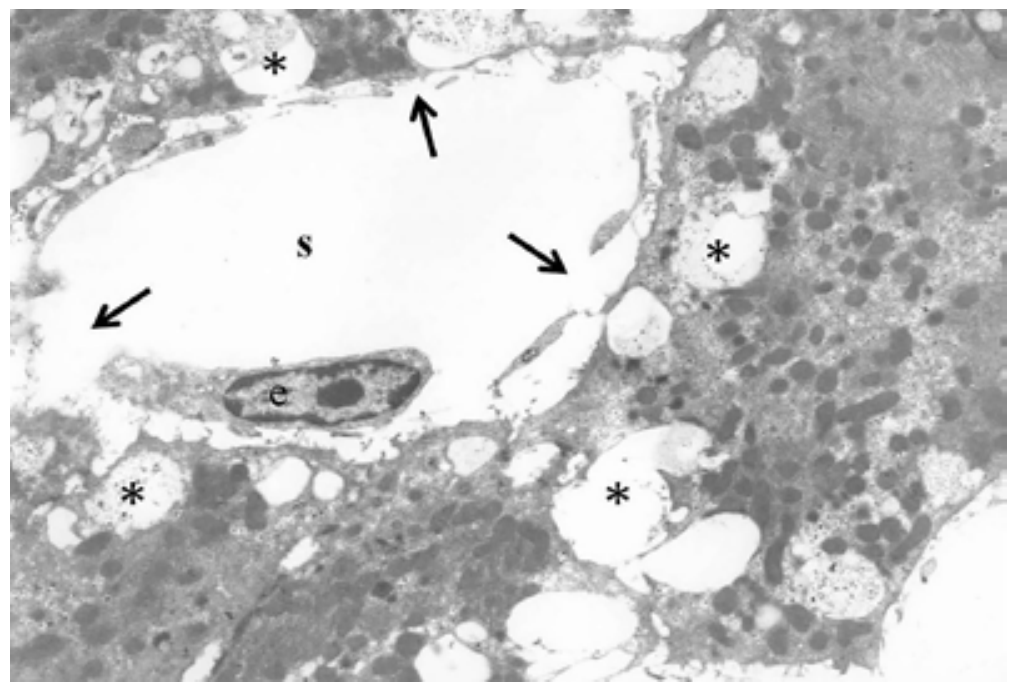

Fig. 3B. Electron micrograph of the liver in the experimental group, $\mathrm{s}$ - sinusoid, e - endothelial cell, black arrows - fenestrations in endothelial cells, asterisks - vesicle, magnification $\times 7000$. 